\title{
Afeto e cidade: Reflexões dos jovens sobre o viver em Sobral (CE)
}

\author{
Affection and city: Young people reflecting on living in Sobral (CE)
}

Nara Maria Forte Diogo Rocha ${ }^{[a]}$, Verônica Salgueiro do Nascimento ${ }^{[b]}$, Alexsandra Maria Sousa Silva ${ }^{[c]}$

\footnotetext{
${ }^{[a]}$ Psicóloga, doutoranda em Educação pela Universidade Federal do Ceará (UFCE), bolsista CAPES/PSDE Universidade do Porto Portugal, professora do curso de Psicologia da Universidade Federal do Ceará (UFCE), Sobral, CE - Brasil, e-mail: narafdiogo@gmail.com

${ }^{[b]}$ Psicóloga, doutora em Educação pela Universidade Federal do Ceará (UFC), professora do Mestrado em Desenvolvimento Regional Sustentável (PRODERUFCA) e do curso de Psicologia da UFC - Sobral, Sobral, CE Brasil, e-mail: vesalgueiro@gmail.com

[c] Psicóloga, mestranda em Psicologia pela Universidade Federal do Ceará (UFCE), Fortaleza, CE - Brasil, e-mail: alelexsandra@hotmail.com
} [d]

Recebido: $15 / 03 / 2012$ Received: 03/15/2012

Aprovado: 25/10/2012 Approved: 10/25/2012

\begin{abstract}
Resumo
Os jovens são cada vez mais chamados a discutir sobre suas vidas nos territórios em que habitam. Esta pesquisa visou investigar as representações afetivas de jovens sobre a cidade onde vivem. Participaram desse estudo 34 sujeitos beneficiados pelo programa federal ProJovem Urbano na cidade de Sobral, Ceará, Brasil. 0 estudo foi realizado durante o segundo semestre de 2010, por iniciativa do Observatório da Infância e Juventude de Sobral, extensão do Curso de Psicologia da Universidade Federal do Ceará. Foram construídos mapas afetivos com os jovens, por meio dos quais se buscou a compreensão psicossocial e sociocultural na relação entre subjetividade e espaço construído, enfatizando o afeto como grande agregador da percepção e do conhecimento sobre a cidade. As imagens apresentadas pelos participantes, em sua maioria, revelam o sentimento de agradabilidade pela cidade, indicando satisfação em viver na cidade. Outro sentimento revelado pelos mapas indica a presença de contrastes, ou seja, o jovem afirma gostar de sua cidade, mas também apresenta preocupações com a degradação ambiental, a ausência de paz e o aumento do vandalismo. Entendemos que os jovens podem assumir papel de protagonistas de ações inclusivas e solidárias; para tanto, faz-se necessária a inclusão desses atores na reflexão e na construção de referenciais para intervenções públicas e privadas interessadas no aumento da qualidade de vida nas regiões urbanas.
\end{abstract}

Palavras-chave: Juventude. Cidade. Afetividade.

\section{Abstract}

Young people are often called to participate in themes of relevance about their lives and the relation with the cities they inhabit. This study aimed to investigate the affective representations of young people about the city where they live. Thirty-four subjects participated in this study, benefited from the federal program ProJovem Urbano in the city of Sobral, Ceará State, Brazil. The study was conducted during the second semester of 2010 and was an initiative of the Centre for Children and Youth from Sobral, extension of the Psychology Course at the Federal University of Ceará. Specifically affective maps were constructed with the subjects, aiming to understand the psychosocial and socio-cultural relationship between subjectivity and the built environment, emphasizing the great affection as aggregator of perception and knowledge of the city. The images 
presented by the participants mostly reveal the feeling of pleasantness by the city indicating satisfaction in living in the city. Another feeling revealed by the maps indicate the presence of contrasts, that is, the young love their city, but also presented concerns about environmental degradation, lack of peace and increased vandalism. We understand that young people can take lead role of inclusive actions and be sympathetic to whatever is necessary to include these actors in the reflection and construction of references to public intervention and private organizations interested in improving the quality of life in urban areas.

Keywords: Youth. City. Urban sustainability.

\section{Introdução}

Este trabalho visou investigar os sentimentos dos jovens participantes do ProJovem Adolescente em Sobral sobre essa cidade. Juventude e adolescência, apesar de serem termos muitas vezes utilizados de forma intercambiável, têm sido referências de grupos populacionais distintos. Na década de 80 , emergiram políticas voltadas para a garantia de direitos de crianças e adolescentes, sendo a adolescência legalmente estabelecida entre 12 e 18 anos. As políticas de juventude têm avançado no Brasil desde a década de 90 , principalmente em virtude da visibilidade que esse segmento populacional tem conseguido, focalizando, sobretudo, aqueles com mais de 18 anos e suas questões relativas à construção da autonomia na vida adulta. Em 2005, o governo federal lançou a Política Nacional de Juventude, da qual faz parte o Programa Nacional de Inclusão de Jovens: Educação, Qualificação e Ação Comunitária (ProJovem).

Esse programa acontece em quatro modalidades: ProJovem Adolescente, ProJovem Urbano, ProJovem do Campo e ProJovem Trabalhador, em razão da diversidade de situações e condições desse segmento tão diverso. 0 trabalho de pesquisa abordou especificamente o ProJovem Adolescente, portanto não pretendemos nos deter aos demais, afirmando apenas que cada um destina-se a uma faixa etária e enfoca questões referentes à especificidade retratada em sua nomenclatura.

De acordo com a Lei n. 11.692, de 2008, o ProJovem Adolescente é a modalidade destinada à faixa etária de 15 a 17 anos dos jovens cujas famílias são beneficiárias do Bolsa Família, são egressos ou estão cumprindo medidas socioeducativas e vêm de outros programas como o PETI ${ }^{1}$. Visa garantir a

\footnotetext{
1 Programa de Erradicação do Trabalho Infantil.
}

proteção social básica, a convivência familiar e comunitária, a reinserção do jovem no sistema escolar, coordenado pelo Ministério do Desenvolvimento Social. Articula três eixos estruturantes: participação cidadã, mundo do trabalho e convivência social, sendo seis os temas transversais trabalhados: direitos humanos e socioassistenciais, trabalho, cultura, meio ambiente e esporte. Dessa forma, tal investigação torna-se relevante posto que os jovens envolvidos, além de estarem em situação de exclusão, procuram assumir, por meio do ProJovem, ações de protagonismo do desenvolvimento da cidade.

Atualmente, a relação entre o homem e o lugar que ocupa tem pautado muitas discussões, principalmente a respeito da urgente necessidade de definir novas relações que contemplem a ótica da sustentabilidade. A participação de todos amplia o exercício da cidadania, por sua vez, entendemos ser essencial a inclusão dos jovens no debate sobre o que a cidade pode oferecer para esse sujeito e quais as possíveis contribuições dos jovens para a construção de ações sustentáveis envolvendo a dimensão do bem viver nas cidades (Gadotti, 2008). Fazse relevante interrogar os jovens a respeito de suas preocupações em relação à cidade que ocupa. Como esse lugar é percebido por eles? Quais os seus sentimentos com relação ao lugar onde vive? A partir dessas interrogações, será lhes feito o convite para expressarem o que pensam e sentem a respeito da temática em foco.

Nesse sentido, acrescentamos que, ao definirmos os jovens como sujeitos de nossa pesquisa, concordamos com Peralva (2007), quando afirma ser necessário olhar os jovens a partir da ótica da positividade. Sobre esse ponto, Abramo (2007) pontua que, na maior parte das abordagens relativas ao trabalho com os jovens, está presente uma grande dificuldade de considerar efetivamente os jovens como sujeitos. Para a autora, isso traduz uma limitação, na 
compreensão desse sujeito, de ir além de sua condição de "problema social" e de incorporá-lo como capaz de formular questões significativas, propor ações relevantes, sustentar uma relação dialógica com outros autores, contribuir para a solução dos problemas sociais, além de simplesmente sofrê-los ou ignorá-los.

De acordo com o posicionamento anterior, Juarez Dayrell (2003) observa que, lamentavelmente, ainda prevalece uma representação negativa e preconceituosa em relação à juventude. "O jovem é visto na perspectiva da falta, da incompletude, da desconfiança, o que torna ainda mais difícil para a escola perceber quem ele é, de fato, o que pensa e é capaz de fazer" (Dayrell, 2003, p. 186). Dessa forma, entende-se necessário e urgente aumentar o número de pesquisas e outras ações que colaborem para afirmar o jovem como sujeito para além da falta e que seu olhar pode ser incluído nas discussões a respeito da condição juvenil.

Ressaltamos que esta pesquisa foi iniciativa do Observatório da Infância e Juventude de Sobral, programa de extensão do Curso de Psicologia da Universidade Federal do Ceará, que tem como principais objetivos construir saberes e articular parceiros em torno da questão da infância e da juventude de Sobral. Como um espaço de troca, criação e reflexão de ações voltadas a crianças e jovens, o Observatório tem como um de seus pressupostos centrais a desnaturalização desses momentos da vida das categorias de análise a elas associadas, primando pelas diversas formas de pertencimento de crianças e jovens em nosso mundo.

Enfatizamos que o objetivo geral deste estudo foi investigar os sentimentos dos jovens do ProJovem Adolescente de Sobral sobre a cidade. Especificamente esperamos elencar e analisar os sentimentos expressos pelos jovens; problematizar a relação do jovem com a cidade e subsidiar a construção de ações públicas para a juventude que incluam os jovens como parte ativa desse pensar e fazer. No decorrer da pesquisa, foram construídos os mapas afetivos com os jovens participantes desse projeto em Sobral e procedeu-se à análise dos mesmos. Ressaltamos que nossa intenção é gerar dados e provocar reflexões sobre eles, divulgando os resultados no meio científico, bem como junto aos participantes. Na próxima parte do texto, discorremos a respeito dos principais conceitos contemplados pelo estudo e nosso referencial teórico.

\section{Quadro teórico}

Infância, adolescência e juventude constituem-se como categorias sociais de relevância a partir da Modernidade, tendo emergido, cada uma a seu tempo, como momentos estratégicos do desenvolvimento humano e, portanto, tornando-se alvo de diversas intervenções, muitas fundamentadas em saberes da Psicologia. Consideramos, portanto, tais noções como históricas e socialmente construídas, tendo a Psicologia influído em suas configurações, também afetadas pelas mudanças sociais e que indicam formas pelas quais a sociedade cuida de sua transformação/manutenção. Com a redemocratização do país, na década de 1980, infâncias e juventudes, assim como outras minorias, passam a compor diferentemente o quadro de preocupações sociais. Contemporaneamente, o reconhecimento das diversas condições e situações destes momentos da vida, bem como o avanço das discussões no sentido de uma análise crítica e contextualizada de tais aspectos, tem exigido do saber psicológico um constante repensar de sua práxis.

A seguir estão explicitadas algumas discussões que colaboram com a compreensão da proposta, situando a questão das juventudes e de sua participação na cidade, entrelaçadas aos conceitos de território e afetividade.

\section{Juventudes}

O jovem, numa visão clássica, é aquele que retarda sua entrada em vários âmbitos e funções sociais, como o trabalho e obrigações familiares, por exemplo, para ocupar-se da preparação de sua vida futura. As transformações socioeconômicas vivenciadas atualmente não permitem a muitos jovens essa condição de "moratória social" (Erikson, 1968). A juventude, no cenário da sociedade contemporânea, de acordo com Melucci (2007), de fato, não é mais somente considerada apenas sob o aspecto de uma condição biológica, mas também sob a compreensão de uma definição cultural.

Com uma importante contribuição na área da sociologia da juventude, Groppo (2008, p. 8) afirma que esse período "Trata-se não apenas de limites etários pretensamente naturais ou objetivos, mas também, e principalmente, de representações simbólicas e situações sociais com suas próprias formas 
que têm importante influência nas sociedades modernas". Ainda nessa perspectiva, o mesmo autor afirma que a categoria social da juventude assume importância fundamental para a possibilidade de compreensão sobre as diversas características presentes nas sociedades modernas, seu funcionamento e suas transformações. Daí reside também meu interesse em aprofundar conhecimentos sobre tal fase evolutiva.

Assinalando a significativa transformação que os jovens têm passado, Peralva (2007) afirma que o jovem migra de um polo onde era percebido como promessa de futuro, para outro lugar, passando a ser visto como modelo cultural do presente. Ainda de acordo com esse autor, "Interrogar essas categorias permite não somente uma melhor compreensão do universo de referências de um grupo etário particular, mas também da nova sociedade transformada pela mutação" (Peralva, 2007, p. 23).

O Núcleo de Opinião Pública (NOP) da Fundação Perseu Abramo (FPA) realizou, em novembro de 1999, uma pesquisa quantitativa com 1.806 jovens de 15 a 24 anos provenientes das nove regiões metropolitanas do Brasil e do Distrito Federal, como parte da investigação sobre o imaginário social brasileiro. Abramo e Venturini (2000) problematizaram duas ideias básicas acerca da juventude, sendo elas a ideia de "passagem" e de "predisposição natural para a rebeldia", à luz dos resultados da pesquisa supracitada. De acordo com os autores, compreender a juventude como passagem implica a noção de busca da identidade, valores, ideias, modos de agir, até a percepção da juventude como momento de instabilidade. Essas compreensões orientam as ações para a juventude no sentido da preparação da vida futura, levando a um retardamento da inserção em diversos âmbitos da vida social.

A ideia de juventude como "predisposta à rebeldia" tem suas raízes, no entender de Abramo e Venturini (2000), na Revolução Francesa e ganha força nos anos 60 , com os movimentos sociais juvenis. Os autores analisam que tais concepções não colaboram para a compreensão da juventude brasileira hoje. Zanetti (2001) caracteriza a realidade dos jovens brasileiros a partir da vivência em um mundo globalizado, que dissolve identidades nacionais e promove hegemonias de países sobre outros. Neste mundo, a televisão e a internet geram expectativas sem mostrar suas possibilidades de realização, contribuindo para o crescimento da insatisfação e dos conflitos. A liberação sexual promovida pela cultura é cerceada pela AIDS e outras doenças sexualmente transmissíveis, gravidez não planejada e os riscos do aborto. As identidades passam a ser fortalecidas nas ruas, nos espaços das gangues e galeras, como proteção da violência que mata cada vez mais jovens.

Por outro lado, no mundo do trabalho, não há vagas, nem nas universidades, nem no mercado formal. De acordo com esse cenário, faz sentido que as preocupações do jovem brasileiro sejam a violência e o desemprego, como demonstrado por Abramo e Venturini (2000). Ainda de acordo com os autores, os jovens também têm esperanças quanto ao futuro, baseando-se no esforço pessoal, no próprio empenho, e pensam que ter experiências importantes no presente é melhor que se preocupar com o futuro. De acordo com Zanetti (2001), 89\% dos jovens expressam atitude negativa diante da realidade atual.

De acordo com a pesquisa da FPA, os jovens consideram a política importante e veem o alcance dela em seu cotidiano; no entanto, não se consideram aptos a influir nas decisões políticas. Abramo e Venturini (2000) atribuem esse fato à forma de se fazer política no Brasil, pautada no não reconhecimento da capacidade de contribuição dos jovens. Há muito mais jovens participando de organizações culturais que de organizações políticas. Os autores encerram sua discussão ressaltando que os desejos de transformação do mundo e a utopia fazem parte da juventude atual, que se considera com energia para participar desse processo. Zanetti (2001) encontra alto índice de atitude revolucionária, apesar do desgaste das instituições políticas.

É válido ainda salientar que "precisamos falar de juventudes no plural, e não de juventude, no singular, para não esquecer as diferenças e desigualdades que atravessam essa condição" (Abramo, 2005, p. 43). Ou seja, há de se respeitar esses jovens em suas especificidades e tentar sempre contextualizar as percepções acerca deles. Velho e Duarte $(2010$, p. 7$)$ reforçam esse pensamento ao declararem: "o plural salienta a complexidade da sociedade moderno-contemporânea, ao mesmo tempo que busca evitar uma simplificação e um empobrecimento das importantes diferenças encontrada e analisadas".

Tal posicionamento vem somar aos que já foram apresentados, com a intenção de reforçar a necessidade de contextualização histórica e cultural 
de qualquer investigação sobre juventude (Frota, 2007, Abramo, 2007).

\section{Juventudes e cidade}

0 município é o lugar onde os indivíduos crescem, vivem, interagem com os outros, constroem sua história baseada no contexto e nos aspectos presentes ao redor. É mais precisamente na comunidade o melhor espaço para constituição e reconhecimento de sua identidade pessoal, social e municipal. Segundo Góis:

A identidade municipal é um aspecto da identidade social, é o sentimento e a noção que o indivíduo tem de pertencer a certo espaço físico-social (município) que o faz e que por ele é feito, e de compreender esta relação como de integração e de diferenciação de si mesmo em relação à coletividade municipal, implicando aí o significado histórico, cultural, valorativo e vivencial dessa pertinência. Contém a consciência do modo de vida do lugar e a capacidade de apropriação desse espaço físico-social (Góis, 2003, p. 95).

Estão claras, portanto, suas vias de encontro com a Psicologia Ambiental, uma vez que, para Moser (1998, p. 121), "a psicologia ambiental estuda a pessoa em seu contexto, tendo como tema central as inter-relações - e não somente as relações - entre a pessoa e o meio ambiente físico e social".

A noção de apropriação, advinda da psicologia histórico-cultural, foi iniciada por Vigotski e desenvolvida por Leontiev, como um mecanismo básico de desenvolvimento do ser humano na passagem do intersubjetivo ao intrassubjetivo, e passa, em Psicologia Ambiental, a ser estudada como apropriação do espaço. Pol (1996) destaca duas vias principais para que a apropriação aconteça: a da ação-transformação e a da identificação simbólica, na qual os sujeitos agem sobre o espaço e identificam-se com aquele lugar transformado pela sua ação.

Aqui as contribuições de Bomfim, Pascual e Ponte (2009) são relevantes, pois agregam a essas noções as questões apontadas pela psicologia histórico-cultural. De acordo com esses autores, "a perspectiva histórico cultural da identidade de lugar entende que além da produção de sentidos e significados sobre o espaço, o que acontece é o reconhecimento do próprio sujeito nesse processo de significação" (Bomfim, Pascual, \& Ponte, 2009).

A Identidade Municipal emerge como fenômeno a ser considerado em ambas as perspectivas. $\mathrm{Na}$ sociedade atual, percebe-se a influência que a globalização, com ênfase no modelo capitalista, exerce sobre os sujeitos que a constituem. Diante disso, os indivíduos distanciam-se de suas raízes históricas e culturais, perdendo ferramentas importantes na constituição de si; bem como se enfraquecem para o embate que é a transformação de sua realidade pessoal e coletiva. A partir da relação com o lugar, sua cultura e sua história, o ser humano se constitui como sujeito, e tais reflexões são apontadas como tarefas históricas para uma Psicologia da Libertação (Martín-Baró, 1998).

Para Cassab (2001), mais do que um lócus onde a subjetividade se produz, a cidade configura possibilidades e restrições, sendo um "outro" constituinte dos sujeitos. Os percursos dos indivíduos pela cidade são definidos por seus lugares de produtores e consumidores, circunscrevendo circuitos de inclusão e exclusão. Ao abordar a vivência dos jovens pobres na cidade, conclui que ela tem sido espaço de risco de vida, onde são negociadas cotidianamente as possibilidades de sobrevivência.

Segundo dados do Censo Demográfico de 2000, no Brasil, a população de jovens entre 15 e 24 anos é de mais de 34 milhões. Representam cerca de $20 \%$ da população brasileira, sendo que $80 \%$ desse total estão na área urbana. De acordo com o Fundo de População das Nações Unidas em 2003, o Brasil seria considerado o quinto país do mundo com maior representação percentual de jovens, considerando a faixa de 10 a 24 anos (cerca de 51 milhões ou 30\% da população total) (Abramo, 2005).

Numericamente, os jovens compõem um grupo significativo de nossa população. No entanto, para além do aspecto quantitativo, tal grupo vem despertando interesse nos pesquisadores também por ser considerado um grupo vulnerável em várias dimensões, estando presente com destaque nas estatísticas de violência, desemprego, gravidez não desejada, falta de acesso a uma escola de qualidade e carências de bens culturais, lazer e esporte. Esse quadro revela-se como preocupante, à medida que os jovens passam a ser referência para ênfases em dimensões problemáticas e não são explorados aspectos como criatividade e disponibilidade para a 
participação social, elementos a serem mais trabalhados com os jovens.

Suscitados pela necessidade de ir ao encontro de um jovem concreto, morador da cidade de Sobral, integrante do ProJovem Adolescente, fomos norteados pelo compromisso de romper com a barreira que fortalece a crença de que o jovem seria um "problema social". Passamos agora a descrever nosso procedimento metodológico.

\section{Metodologia}

Contexto

A cidade de Sobral foi criada em 1772, situa-se a noroeste no Estado do Ceará, a $224 \mathrm{~km}$ da capital do estado. 0 acesso é feito pela rodovia BR-222, que liga o Ceará ao Piauí e, consequentemente, ao Maranhão e ao Pará. Existe também uma ferrovia, atualmente usada, sobretudo, pelo grupo Votorantim. Em 2009, registrou o total de 182.431 mil habitantes. A população urbana é de 103.868 mil habitantes (81,47\%). A população rural é de 23.621 mil habitantes (18,53\%). Possui uma área absoluta de 2.122,98 $\mathrm{km}^{2}$. Tem altitude de $69,49 \mathrm{~m}^{2}$. 0 clima tem uma variação entre tropical quente semiárido e tropical quente semiárido brando. Em 2007, seu Produto Interno Bruto (PIB) foi de 1.752.648,00 obtendo o posto de terceira economia do estado.

O ProJovem Adolescente em Sobral é executado pela Fundação de Ação Social (FASM), órgão administrativo da Prefeitura de Sobral e conta com 1.400 jovens em 56 coletivos. São 30 coletivos de 25 jovens na sede e 26 coletivos nos distritos. Os coletivos se encontram diariamente (excluindo sábados, domingos e feriados), com o apoio dos Centros de Referência da Assistência Social. Há um orientador contratado pela FASM e responsável por cada coletivo e que coordena os encontros, e um facilitador, responsável por trabalhar temáticas ligadas à saúde, educação, cultura, meio ambiente, dentre outras, definidas pelo Ministério do Desenvolvimento Social.

\section{Participantes}

Como se trata de uma pesquisa de natureza qualitativa, em que a construção dos dados se estabelece no diálogo entre participante e pesquisador
(González-Rey, 2002), os critérios de escolha dos participantes foram: fazer parte do ProJovem Adolescente em Sobral e desejar produzir o mapa afetivo.

Instrumentos

Os mapas afetivos, de acordo com Bomfim (2010), constituem uma metodologia que visa, a partir da captura de imagens e palavras, utilizar as representações para compreender as relações entre os sentimentos e o espaço.

Os desenhos e metáforas são recursos imagéticos reveladores dos afetos que, juntamente com a linguagem escrita dos indivíduos pesquisados, nos dão um movimento de síntese do sentimento. 0 desenho é a criação de uma situação de aquecimento para a expressão de emoções e sentimentos e a escrita traduz a dimensão afetiva do desenho. As metáforas são recursos de síntese, aglutinadores da relação entre significados qualidades e sentimentos atribuídos aos desenhos (Bomfim, 2010, p. 137).

Foi entregue aos participantes uma folha de papel A4. Pediu-se que eles representassem em um desenho a cidade onde moram. Estiveram disponibilizados materiais como lápis de cor e canetas hidrocor. No verso dessa folha, encontravam-se as seguintes questões:

1) O que significa seu desenho?

2) Que sentimentos ele representa?

3) Que palavras resumem seus sentimentos?

4) 0 que você pensa da cidade?

5) A que você compara esta cidade?

6) Que caminhos da cidade você percorre em seu cotidiano?

7) Você participa de associações, grupos comunitários, esportivos ou religiosos? Quais?

8) Você participa de movimentos sociais?

9) Sexo ( ) M ( ) F Idade:

10) Origem, cidade e estado de residência habitual:

11) Tempo de residência na cidade:

12) Escolaridade:

Não foi solicitada identificação. 0 jovem assinou o termo de consentimento livre e esclarecido, 
conforme orientado na submissão ao Comitê de Ética em Pesquisa. Os mapas foram analisados mediante o quadro de análise apresentado por Bonfim (2010, p. 151), no qual constaram dados de identificação do desenho, estrutura (cognitivos ou metafóricos), significado atribuído pelo autor, qualidades atribuídas, sentimentos expressos, metáforas presentes e sentido (síntese dessas categorias).

A seguir, são discutidos os resultados construídos com base nas informações provenientes desse percurso, à luz das teorias que dão suporte a este estudo.

\section{Discussão e resultados}

Inicialmente, situamos a cidade de Sobral em termos de contexto e história para, a seguir, relacionarmos os sentimentos dos jovens com a vivência desse lugar.

\section{Os jovens e a cidade}

A cidade de Sobral pode ser considerada um excelente exemplo da problemática atual no que diz respeito aos conflitos entre lógicas globais e locais. De acordo com Ferreira (2010), a cidade destaca-se no interior do Ceará pela história de privilégio político-econômico, pelo patrimônio arquitetônico, legado da aristocracia local dos séculos XVIII e XIX e por ser a primeira cidade cearense a ser tombada como patrimônio histórico nacional. Concentra um polo industrial, uma forte movimentação comercial, constitui-se um núcleo central para a região em termos educacionais, com a presença de universidades e escolas públicas e privadas e o centro de educação tecnológica, além de ser estratégica em termos de saúde, pela presença de hospitais regionais. A partir do fim dos anos 90, o grupo político que assume a cidade implementa uma série de medidas de requalificação urbana no sentido da modernização dos espaços urbanos por meio de grandes obras, objetivando o consumo visual do espaço e do tempo. Assim:

Sobral tem "Arco do Triunfo" (de Nossa Senhora), "MIT" e "Cristo Redentor". Sobral tem "revitalização" da Beira-Rio, tem condomínio fechado, condomínio vertical embargado (por contravenção ecológica), te internet grátis na praça (em breve terá sem fio por toda a cidade), Sobral tem remoção de população pobre, tem indústria "deslocalizada", tem lavadeiras estendendo roupas nas calçadas reluzentes do parque, tem casa-museu de bispo ultraconservador que sonhava fazer da cidade sua Pequena-Roma. (Haesbert, 2010, p. 214)

A união entre a "tradição" e a "modernidade" resulta, contudo, na sensação de que a incoerência que Haesbert (2010) caracterizou como espacialmente esquizofrênica, devido à contrastante opulência aparente em choque com a aridez e pobreza do sertão cearense, que oculta as contradições internas a si mesma, nas imagens que ostenta e consome. Escreve o autor:

Encontrar internet grátis, sem fio, para todos os que não têm computador, nem transporte público, nem esgotamento sanitário; construir parques assépticos, museus e bibliotecas arquitetonicamente ostensivos, de "primeiro-mundo" com cascatas de água límpida que se projetam sobre um lago poluído por esgotos sem tratamento, onde resistem lavadeiras analfabetas que coram suas roupas sobre as calçadas impecáveis do parque... Paus de arara e moto-táxis suprem a crônica deficiência de transporte público, postos de saúde ajardinados com médicos mal pagos denunciam que mais vale é a imagem (Haesbert, 2010, p. 215).

Surpreendentemente, os mapas afetivos produzidos pelos jovens pesquisados passam ao largo de exprimir as violentas contradições que marcam a cidade. Examinamos a seguir as categorias marcantes atribuídas pelos jovens à cidade.

\section{0 agradável contraste de viver em Sobral}

Os principais sentimentos expressos foram agradabilidade e contraste, categorizados de acordo com a Escala Likert, elaborada por Bomfim (2010). Dessa escala os sentimentos não expressos pelos jovens participantes foram pertencimento e insegurança. A categoria agradabilidade expressa sentimentos de vinculação e qualidades positivas da 
cidade. Foram ressaltadas pelos jovens pesquisados as características da beleza da cidade, cujos exemplos foram os marcos históricos simbólicos da cidade. Outro sentimento revelado pelos mapas indica a presença de contrastes, ou seja, o jovem afirma gostar de sua cidade, mas também apresenta preocupações com degradação ambiental, ausência de paz e aumento do vandalismo.

Como podemos compreender a ausência das categorias pertencimento e insegurança? Esta pesquisa abre novos questionamentos e mais permite a elaboração de outras perguntas do que enseja respostas. Como se forja essa visão de mundo? De que lugar fala esse jovem? 0 que no processo educativo do ProJovem em Sobral os mobiliza?

A beleza da cidade está em seus cartões postais, que retratam, sobretudo no caso de Sobral, réplicas de monumentos de outras partes do mundo. Poderíamos entender esse fenômeno como reflexo da homogeneização sob insígnia de globalização que uniformiza os olhares produzindo um crivo estético onde o sentimento de beleza foi colonizado. A beleza está lá fora, é do outro. Que acesso e que circulação tem o jovem sobralense nesses espaços, quando a cidade não tem transporte público? Que espetacularização se produz quando toda uma estrutura precisa ser montada para que se passeie por esses monumentos, uma vez que os territórios onde estes jovens vivem são distantes desses pontos?

Os jovens apontam o vandalismo, a ausência de paz e a degradação ambiental como preocupantes. É preciso dizer que esses atos são atribuídos também aos jovens. Se analisarmos a pauta de assuntos do ProJovem, por exemplo, podemos notar um considerável esforço no sentido de produzir sentimentos de pertencimento e consciência crítica. Perguntamo-nos, porém, para o que apontam esse vandalismo, essa ausência de paz e essa degradação ambiental, nesse dado contexto e nesse dado momento? Seriam eles indicadores de falta de apropriação desse espaço, de um não reconhecer-se parte desta cidade? 0 vandalismo que preocupa é o da marca das gangues deixadas pela cidade. A falta de paz não expressaria o que a canção a seguir muito bem anuncia?

A minha alma tá armada e apontada para a cara do sossego

Pois paz sem voz, paz sem voz, não é paz é medo
Às vezes eu falo com a vida, às vezes é ela quem diz

Qual a paz que eu não quero conservar para tentar ser feliz

As grades do condomínio são para trazer proteção

Mas também trazem a dúvida se é você que está nessa prisão

Me abrace e me dê um beijo faça um filho comigo

Mas não me deixe sentar na poltrona no dia de domingo, domingo

Procurando novas drogas de aluguel nesse

vídeo coagido

É pela paz que eu não quero seguir admitindo (Marcelo Yuka)

Talvez nem tudo seja tão agradável em Sobral e os contrastes insistam em aparecer, mesmo que sob certa anestesia do cotidiano. Há algo que lateja sob a aparente paz desejada, paz talvez inalcançável em um contexto que exija o silenciamento dos contrastes apontados pelos jovens. 0 sentimento de insegurança também não é ressaltado pelos jovens, ou seja, o medo ainda não é forte a ponto de apagar as possibilidades de uma vida melhor na cidade. Do contraste, da polarização de emoções positivas e negativas, podemos inferir o movimento de uma consciência inquieta. A realidade já não parece natural para alguns jovens e o entorpecimento ao qual se refere a canção/poesia citada acima, também não os interessa. Falar sobre estes contraste é começar a construir uma paz com voz, uma paz animada, na qual a alma, ou seja, o sentido - a amálgama do singular e do coletivo, da razão e da sensibilidade seja a arma, o instrumento que ameace a agradável indolência do espectador de um desenvolvimento que ele próprio não sabe e não sente como sustenta e também por isso também não reivindica seus direitos sobre ele.

\section{Considerações finais}

Como conclusão, entendemos que buscamos a compreensão psicossocial e sociocultural na relação entre subjetividade e espaço construído, enfatizando o afeto como grande agregador da percepção 
e do conhecimento sobre a cidade. Um dos objetivos deste estudo seria subsidiar a construção de ações públicas que incluam os jovens como atores.

Entendemos que eles podem assumir papel de protagonistas de ações inclusivas e solidárias. Para tanto, faz-se necessária a inclusão desses atores na reflexão e na construção de referenciais para intervenções públicas e privadas interessadas no aumento da qualidade de vida nas regiões urbanas. Tal processo encontra-se iniciado por sua inserção nas políticas públicas por meio da participação no ProJovem, e precisa enraizar-se alimentando a rede que possibilite o aprofundamento de suas consciências e seus afetos em relação à construção da cidade.

Para isso, apontamos as compreensões aqui referidas, de que consciência e sentimentos não são processos avessos um ao outro, de que os sentimentos nos informam como ocupamos o mundo. O poema de Cecília Meireles nos faz pensar sobre a sustentabilidade:

No mistério do sem-fim equilibra-se um planeta.

E, no planeta, um jardim, e, no jardim, um canteiro; no canteiro uma violeta, e, sobre ela, o dia inteiro,

entre o planeta e o sem-fim, a asa de uma borboleta.

(Cecília Meireles)

A delicadeza da metáfora que a poesia nos traz dimensiona o desafio ao qual essa delicadeza nos convida. Construir a sustentabilidade é um trabalho fino, de encontrar acordo e equilíbrio entre vidas, possibilitando uma que aconteça em um lugar melhor. A realidade enfrentada cotidianamente é dura, difícil e, muitas vezes, irredutível para os jovens impedidos de uma inserção digna. As contribuições juvenis para a transformação desse lugar muitas vezes são perdidas no cumprimento das burocracias que regem a execução das políticas públicas unidirecionais (do federal para o municipal) e quantitativas. Para que as políticas se enraízem e alcancem os cotidianos, gerando a sustentabilidade desejada, é preciso a que a participação juvenil ultrapasse os níveis figurativos e consultivos, traduzindo-se em pontos de inflexão das pautas a serem implementadas. Em última instância, a sustentabilidade está ancorada na autonomia.

\section{Referências}

Abramo, H. W. (2007). Considerações sobre a tematização social da juventude no Brasil. In O. Fávero, M. P. Spósito, P. Carrano, R. R. Novaes (Org.). Juventude e contemporaneidade (pp. 73-90). Brasília: Unesco/ MEC/ANPEd.

Abramo, H. (2005). Condição juvenil no Brasil contemporâneo. In H. Abramo \& P. Branco (Org.). Retratos da juventude brasileira: Análises de uma pesquisa nacional. São Paulo: Editora Fundação Perseu Abramo/ Instituto Cidadania.

Abramo, H., \& Venturini, G. (2000). Juventude, política e cultura. Revista Teoria e Debate, (45). Recuperado em 3 de abril, 2014, de http:// www.teoriaedebate.org.br/materias/sociedade/ juventude-politica-e-cultura?page $=0,1$

Bomfim, Z. A. C. (2010). Cidade e afetividade: Estima e construção dos mapas afetivos de Barcelona e de São Paulo. Fortaleza: Edições UFC.

Bomfim, Z. A. C., Pascual, J. G., \& Ponte, A. Q. (2009) Considerações teóricas sobre identidade de lugar à luz da abordagem histórico-cultural. Psicologia Argumento, 27(59), 345-354.

Cassab, M. A. T. (2001). Jovens pobres e a cidade: A construção da subjetividade na desigualdade. In L. R. Castro. Crianças e jovens na construção da cultura. Rio de Janeiro: Nau Editora/Faperj Editora.

Dayrell, J. (2003) Escolas e culturas juvenis. In M. Freitas \& F. Papa (Org.). Políticas públicas: Juventude em pauta. São Paulo: Cortez.

Erikson, E. (1968). Identidade: Juventude e crise. Rio de Janeiro: Zahar.

Ferreira, D. L. (2010). Espaços de lazer em Sobral - Ceará: 0 "Cid marketing" e uma proposta de (re)invenção da cidade. In M. M. Júnior, N. A.Freitas \& V. C. Holanda. Múltiplos olhares sobre a cidade e o urbano: Sobral e região em foco. Sobral: UECE/UVA. 
Frota, A. M. M. C. (2007) Diferentes concepções da infância e da adolescência: A importância da historicidade para sua construção. Estudos e Pesquisas em Psicologia, 7(1), 144-157.

Gadotti, M. (2008) Educar para a sustentabilidade: Uma contribuição à década da educação para o desenvolvimento sustentável. São Paulo: Editora e Livraria Instituto Paulo Freire.

Góis, C. W. L. (2003). Psicologia comunitária no Ceará. Fortaleza: Publicações Instituto Paulo Freire.

González-Rey, F. L. (2002). Pesquisa qualitativa em psicologia. São Paulo: Pioneira Thomson Learning.

Groppo, L. A. (2000). Juventude: Ensaio sobre sociologia e história das juventudes modernas. Rio de Janeiro: DIFEL

Haesbert, R. (2010) Sobral: Esquizofrenia da exceção. In M. M. Júnior, N. A. Freitas \& V.C. Holanda. Múltiplos olhares sobre a cidade e o urbano: Sobral e região em foco. Sobral: UECE/UVA.

Martín-Baró, I. (1998). Psicología de la liberación. Madrid: Editorial Trotta.
Melucci, A. (2007). Juventude, tempo e movimentos sociais. In O. Fávero, M. P. Spósito, P. Carrano, R. R. Novaes (Org.). Juventude e contemporaneidade (pp. 29-45). Brasília: Unesco/MEC/ANPEd.

Moser, G. (1998). Psicologia Ambiental. Estudos de Psicologia, 3(1), p. 121-130.

Peralva, A. (2007). 0 jovem como modelo cultural. In 0. Fávero, M. P. Spósito, P. Carrano, R. R. Novaes (Org.). Juventude e contemporaneidade (pp. 13-27). Brasília: Unesco/MEC/ANPEd.

Pol, E. (1996). La apropriación del espacio. In: L. Iñiguez \& E. Pol (Ed.). Cognición, representación y apropiación del espacio (pp. 45-62). Barcelona: Publicacions Universitat de Barcelona.

Velho, G., \& Duarte, L. F. D. (2010). Juventude contemporânea: Culturas, gostos e carreiras. Rio de Janeiro: 7 letras.

Zanetti, H. (2001). Juventude e revolução: Uma investigação sobre a atitude revolucionária juvenil no Brasil. Brasília: Editora Universidade de Brasília. 